\section{Range-Energy and Other Relations for Elec- trons in Kodak Nuclear Plates}

KODAK Nuclear Track plates of type NTP 2,30 $\mu$ in thickness, have been exposed in a low-resolution $\beta$-ray spectrograph using uniform magnetic fields of 279 and 302 oersteds. The focused line had a half-breadth of about $1 \mathrm{~mm}$. The rays entered the plate at a grazing angle, the central ray meeting the plate at $6^{\circ}$. 'Line' sources of thorium $(B+C)$ and radium $E$ were used to provide continuous spectra. Exposure times were such as to give, in the $80-\mathrm{keV}$. energy region, about $2 \times 10^{5} \beta$-rays per sq. $\mathrm{cm}$. on a surface normal to the central ray. The plates were developed for $20 \mathrm{~min}$. at $18^{\circ} \mathrm{C}$. in 'Kodinol' developer.

Emulsions of two different sensitivities were used, the normal NTP $2 \alpha$, and an experimental emulsion having larger grains and higher sensitivity than the NTP 2a. The chemical constitution of the two emulsions was the same. In the $N T P 2 a$ plates, electron tracks could be followed easily up to $50 \mathrm{keV}$., and with some difficulty up to $80 \mathrm{keV}$. energy. In the more sensitive emulsion, the upper energy limit for the range measurements was set by the thickness of the emulsion. The longest observed track was of $\mathbf{9 4 . 4} \mu$ with corresponding energy almost certainly greater than $150 \mathrm{keV}$. (see below). Fig. 1, from a radium E plate, shows a 'background' track (prob. ably of a secondary electron due to high-energy Bremsstrahlung). This track is $81.4 \mu$ long and contains about 65 grains. Fig. 2 shows an $80-\mathrm{keV}$. track from radium $\mathrm{E}(27 \cdot 8 \mu$ and 32 grains).

Measurements were made of the ranges of unbranched tracks (a branch could not be identified with certainty if its energy were below about $20 \mathrm{keV}$.) starting in the surface of the emulsion and having

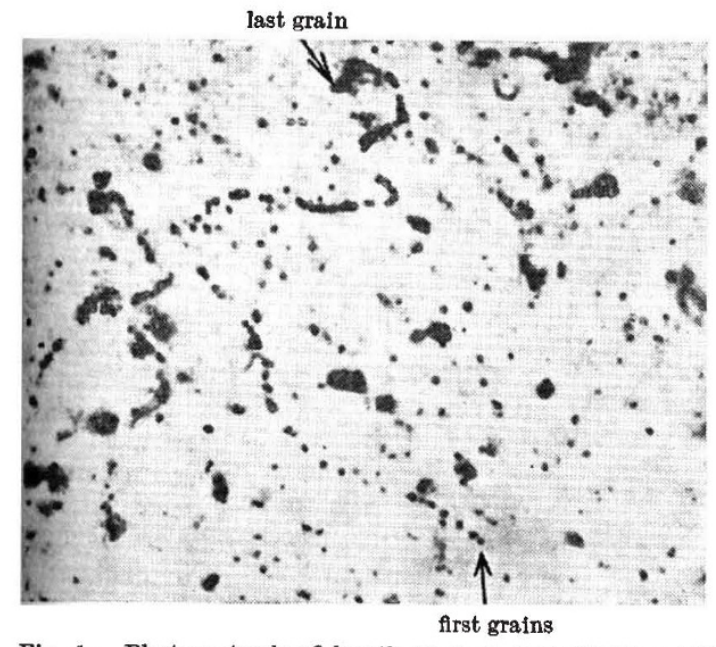

Fig. 1. Electron track of length $81 \cdot 4 \mu$; magniflcation 1,260

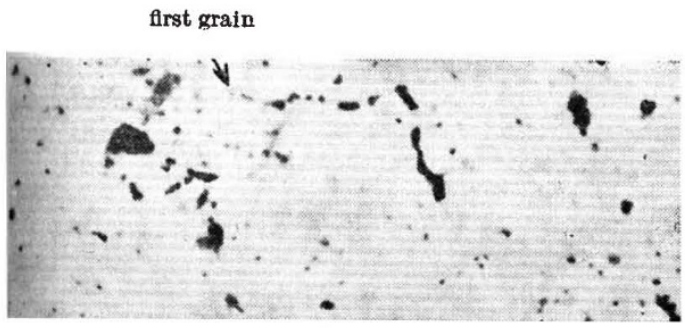

Fig. 2. Electron track of $80-\mathrm{keV}$. energy ; magniflcation 1,260 an initial direction within $40^{\circ}$ of the central ray direction. Working from grain to grain, observations were made of projected lengths and differences of depths. Depth measurements were corrected for shrinkage of the emulsion in processing. The range data from the higher sensitivity plates are given in Table 1. Because of the limited thickness of the emulsion, the $100 \mathrm{keV}$. range may be somewhat low, and is therefore enclosed in brackets.

\begin{tabular}{|c|c|c|c|c|c|}
\hline $\begin{array}{c}\text { No. of } \\
\text { tracks } \\
\text { ob- } \\
\text { served }\end{array}$ & $\begin{array}{c}\text { Mean } \\
\text { energy } \\
\text { of } \\
\text { tracks } \\
\text { (keV.) }\end{array}$ & $\begin{array}{l}\text { Mean range } \\
\text { of tracks } \\
(\mu)^{*}\end{array}$ & $\begin{array}{l}\text { Standard } \\
\text { deviation } \\
\text { of ranges }\end{array}$ & $\begin{array}{l}\text { Mean No. } \\
\text { of grains } \\
\text { per track* }\end{array}$ & $\begin{array}{c}\text { Standard } \\
\text { deviation } \\
\text { of number } \\
\text { of grains }\end{array}$ \\
\hline $\begin{array}{l}25 \\
25 \\
25 \\
25 \\
25 \\
25\end{array}$ & $\begin{array}{r}30 \\
40 \\
50 \\
60 \\
80 \\
100\end{array}$ & $\begin{array}{r}6 \cdot 90 \pm 0 \cdot 33 \\
11 \cdot 00 \pm 0 \cdot 57 \\
15 \cdot 78 \pm 0 \cdot 50 \\
22 \cdot 15 \pm 1 \cdot 12 \\
32 \cdot 65 \pm 1 \cdot 55 \\
(42 \cdot 09 \pm 1 \cdot 99)\end{array}$ & $\begin{array}{l}1 \cdot 67 \\
2 \cdot 84 \\
2 \cdot 51 \\
5 \cdot 62 \\
7 \cdot 74 \\
9 \cdot 94\end{array}$ & $\begin{array}{l}10 \cdot 8 \pm 0 \cdot 4 \\
14 \cdot 4 \pm 0 \cdot 4 \\
20 \cdot 4 \pm 0 \cdot 7 \\
22 \cdot 4 \pm 1 \cdot 0 \\
35 \cdot 5 \pm 1 \cdot 4 \\
41 \cdot 0 \pm 1 \cdot 6\end{array}$ & $\begin{array}{l}2 \cdot 0 \\
2 \cdot 0 \\
3 \cdot 6 \\
4 \cdot 9 \\
6 \cdot 9 \\
7 \cdot 9\end{array}$ \\
\hline
\end{tabular}

* With standard error.

The grain density along the $100-\mathrm{keV}$. tracks was analysed in $5 \mu$ portions of the tracks, working back. wards from the last grain of the track. The results are given in Table 2.

Table 2

\begin{tabular}{|c|c|c|}
\hline $\begin{array}{c}\text { Portion of track } \\
\text { from the last grain }\end{array}$ & $\begin{array}{c}\text { Mean number of } \\
\text { grains per 5 } \mu^{*}\end{array}$ & $\begin{array}{c}\text { Standard deviation } \\
\text { of number of grains }\end{array}$ \\
\hline $0-5 \mu$ & $7 \cdot 0 \pm 0 \cdot 3$ & $1 \cdot 7$ \\
$5-10$ & $5 \cdot 3 \pm 0 \cdot 3$ & $1 \cdot 3$ \\
$10-15$ & $5 \cdot 2 \pm 0 \cdot 3$ & $2 \cdot 5$ \\
$15-20$ & $4 \cdot 6 \pm 0 \cdot 3$ & $1 \cdot 3$ \\
$20--25$ & $4 \cdot 3 \pm 0 \cdot 2$ & $1 \cdot 0$ \\
$25-30$ & $4 \cdot 3 \pm 0 \cdot 3$ & $1 \cdot 3$ \\
$30-35$ & $4 \cdot 1 \pm 0 \cdot 3$ & $1 \cdot 1$ \\
$35-40$ & $3 \cdot 7 \pm 0 \cdot 3$ & $1 \cdot 0$ \\
\hline
\end{tabular}

The relative stopping power of the emulsion may be defined as $\Delta R_{a} / \Delta R$, where $\Delta R_{a}$ is change of range in air at $760 \mathrm{~mm}$. mercury pressure and $15^{\circ} \mathrm{C}$., and $\Delta R$ is change of range in emulsion for the same change of energy of the $\beta$-particles from $V_{A}$ to $V_{B}$. Thus defined, the relative stopping power is a function of the mean energy $V=\frac{1}{2}\left(V_{A}+V_{B}\right)$. Values of relative stopping power given in Table 3 were deduced from the data in Table 1 and from calculated mean ranges of electrons in air given by Tsien, Marty and Dreyfus ${ }^{1}$, and shown by Tsien ${ }^{2}$ to be in close agreement with experimental values in the region of energy up to $50 \mathrm{keV}$. If the $100-\mathrm{keV}$. range in Table 1 is low, the $90-\mathrm{keV}$. stopping power in Table 3 will be high.

Table 3

\begin{tabular}{|c|c|}
\hline$V$ in keV. & $\begin{array}{c}\text { Relative stopping power of emulsions, } \\
\text { with standard error }\end{array}$ \\
\hline 35 & $2640 \pm 420$ \\
45 & $2720 \pm 430$ \\
55 & $2290 \pm 440$ \\
70 & $3130 \pm 570$ \\
90 & $(3840 \pm 1030)$ \\
\hline
\end{tabular}

MARION A. S. Ross

Barbara ZaJaC

Department of Natural Philosophy, University,

Edinburgh. Oct. 23.

'Tsien San-Tsiang, Marty, C., and Dreyfus, B., J. Phys. et le Rad. 8, 269 (1947)

2 Tsien San-Tsiang, Ann. de Physique, 19, 327 (1944). 